\title{
Perencanaan Lansekap Wisata Berbasis Edukasi Mangrove di Restoran Akame, Benoa
}

\author{
I MADE ADI PRANATHA ${ }^{1}$, I WAYAN ARTHANA ${ }^{2 \star}$ \\ NI WAYAN FEBRIANA UTAMI ${ }^{1}$
}

1. Program Studi Arsitektur Pertamanan, Fakultas Pertanian, Universitas Udayana JI. PB. Sudirman Denpasar 80362, Bali

2. Program Studi Manajemen Sumberdaya Perairan, Fakultas Perikanan dan IImu Kelautan, Universitas Udayana. Jl. Kampus Bukit Jimbaran 80361, Bali

*Email: arthanaunud@gmail.com

\section{ABSTRACT \\ Tourism Landscape Planning Based on Education of Mangrove at Akame Restaurant, Benoa}

Some regional development in Benoa area utilize mangrove areas. One of them is the development of the Akame Restaurant. This restaurant development greatly affects the existence of mangroves so as to reduce the negative impacts caused by the development of the restaurant then it should be based on regional planning and conservation education to become a sustainable development of the business and tourist area. Planning research method consists of several stages of inventory, analysis, synthesis, concepts and travel planning. Identification and analysis of the potential and constraints of biophysical, economic, social and cultural development in the tourist landscape Akame Restaurant produces spatial concept. The concepts consist of circulation and the concept of infrastructure that supports the activities of the restaurant and the activities of mangrove educational tours. Objects and attraction that are planned include the cultivation of mangrove crabs, bird watching, planting mangrove seedlings, outbound, and canoeing.

Keywords: akame restaurant, landscape planning, landscape tourism, mangrove education

\section{Pendahuluan}

Hutan mangrove sebagai salah satu ekosistem wilayah pesisir dan lautan sangat potensial bagi kesejahteraan masyarakat baik dari segi ekonomi, sosial dan lingkungan hidup, namun sudah semakin kritis ketersediaannya.

Bali selatan mempunyai mangrove seluas $1.373,50 \mathrm{Ha}$ yang berada dikawasan hutan Prapat Benoa Kota Denpasar dan Kabupaten Badung (DPA Dinas Kehutanan Bali, 2008). Mangrove ini sangat strategis ditinjau dari segi konservasi karena posisinya tepat melindungi pesisir mulai kawasan Sanur (Kota Denpasar) hingga Nusa Dua (Badung) sepanjang kurang lebih $47 \mathrm{Km}$, dengan lebar antara $100 \mathrm{~m}-1.000 \mathrm{~m}$. Keberadaan mangrove di Bali selatan terancam mengalami penurunan diakibatkan oleh cara-cara 
pemanfaatan hutan mangrove yang cenderung merusak, sehingga menyebabkan penurunan luas hutan mangrove dari waktu kewaktu. Kemudian pengembangan kawasan di daerah Benoa banyak memanfaatkan kawasan mangrove, salah satunya adalah pengembangan di kawasan Restoran Akame. Restoran Akame terletak di jalan pelabuhan Benoa, Pesanggaran Denpasar. Pengembangan restoran ini sangat mempengaruhi keberadaan mangrove, sehingga untuk mengurangi dampak negatif yang ditimbulkan akibat pengembangan restoran maka harus dilakukan perencanaan kawasan yang berbasis edukasi dan konservasi sehingga menjadi pengembangan yang berkelanjutan.

Agar berlanjut, maka perencanaan lansekapnya menjadi penting karena merupakan kegiatan penataan yang berbasis lahan (land base planning) melalui kegiatan pemecahan masalah dan merupakan pengambilan keputusan jangka panjang guna mendapatkan suatu model lansekap yang fungsional, estetik dan lestari yang mendukung berbagai kebutuhan dan keinginan manusia. Perencanaan dilakukan untuk sekaligus juga dalam upaya meningkatkan kenyamanan dan kesejahteraan (Nurisjah dan Pramukanto, 2001) yang terkait dengan program wisata dan mangrovenya.

Wisata hutan mangrove merupakan suatu bentuk kegiatan berwisata dengan melakukan perjalanan mengelilingi area hutan mangrove serta menikmati segala keunikan yang terdapat di dalamnya (Ambara, 2009). Hutan mangrove sebagai salah satu kawasan wisata memiliki fungsi sebagai tempat berwisata bagi wisatawan lokal maupun mancanegara, dengan fasilitas-fasilitas yang disediakan pengelola. Kawasan mangrove dengan keragaman jenis tumbuhan bakau serta satwanya dapat memberikan kegiatan berwisata yang khas serta memberikan wawasan dan pengalaman dengan suasana yang berbeda. Jenis-jenis wisata atau potensi wisata yang ditawarkan hutan mangrove sebagai salah satu kawasan obyek wisata antara lain wisata bird watching, memancing, tracking/lintas alam, menikmati pemandangan dan keanekaragaman karakteristik tanaman bakau yang menjadi daya tarik wisata mangrove. Jenis-jenis wisata yang seperti itulah yang ingin dikembangkan di kawasan Restoran Akame.

Tujuan dari penelitian ini untuk mengetahui potensi dan kendala pada aspek biofisik, ekonomi, dan sosial budaya terhadap pengembangan lansekap wisata Restoran Akame dan dapat menentukan konsep perencanaan lansekap wisata berbasis edukasi mangrove yang sesuai untuk pengembangan Restoran Akame.

\section{Bahan dan Metode}

Konsep dasar perencanaan kawasan wisata mangrove di Restoran Akame adalah merencanakan sebuah kawasan wisata yang edukatif yang dapat memberikan suatu pembelajaran kepada para pengunjung khususnya mengenai tanaman dan lingkungan mangrove sebagai upaya untuk menciptakan kawasan yang berkelanjutan, sedangkan konsep pengembangannya merupakan penjabaran dari konsep dasar yang dibagi menjadi beberapa konsep yaitu konsep ruang, konsep sirkulasi dan konsep tata sarana dan prasarana.

Bahan yang digunakan berupa denah lokasi dan foto Restoran Akame. Alat yang digunakan dalam penelitian ini adalah kamera digital dan komputer dengan piranti lunak 
berupa Autocad 2008, Corel Draw X5, Sketchup Pro 8 with Vray render dan Google Earth. Metode penelitian perencanaan kawasan wisata terdiri dari beberapa tahapan yaitu inventarisasi, analisis, sintesis, konsep dan perencanaan wisata. Studi perencanaan dilakukan dengan menggunakan pendekatan perencanaan komponen pengembangan pariwisata (Inskeep,1991).

\section{Hasil dan Pembahasan}

\subsection{Hasil}

Hasil penelitian dari perencanaan wisata edukasi mangrove di Restoran Akame trrdiri dari inventaris, analisis, batas tapak, aspek biofisik, aspek ekonomi, aspek sosial dan budaya.

\subsubsection{Inventaris dan Analisis}

Restoran Akame berada dalam kawasan Desa Pesanggaran tepatnya sebelah utara dari pelabuhan Benoa. Kawasan Restoran Akame memiliki luas kurang lebih 6 ha dengan batas wilayah sebelah utara Desa Pedungan, batas timur pulau Serangan, batas selatan Pelabuhan Benoa dan batas barat Jalan Pelabuhan Benoa. Lokasi yang direncanakan untuk lansekap wisata yaitu sebelah timur dari bangunan restoran yaitu bekas tambak ikan yang dekat dengan mangrove. Aksesibilitas menuju Restoran Akame sangat mudah dijangkau karena berada di Jalan Pelabuhan Benoa yaitu jalan menuju akses tol Bali Mandara. Peta dan batas lokasi penelitian dapat dilihat pada Gambar 1.
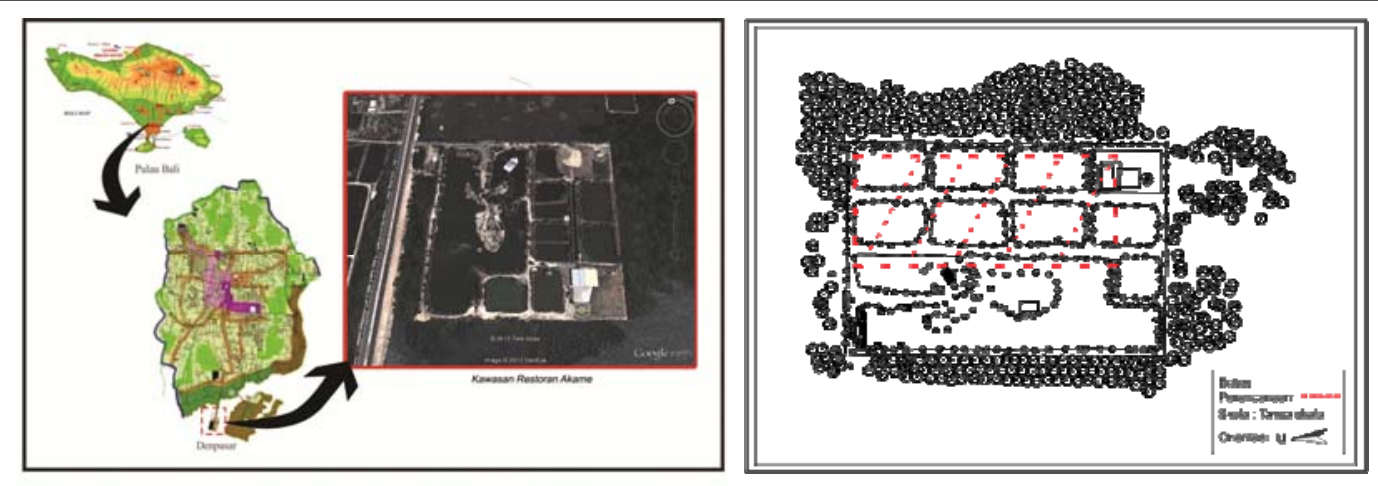

Gambar 1. Peta dan Batas Lokasi Penelitian

Batas perencanaan tapak yaitu lahan yang berada di sebelah timur dari bangunan restoran yang telah ada sekarang (dapat dilihat pada Gambar 1). Luas lahan yang akan direncanakan $\pm 1,8$ ha. Lahan yang saat ini ada dilokasi perencanaan meliputi bekas kolam-kolam tambak yang difungsikan sebagai kolam pembesaran ikan.

\subsubsection{Aspek Biofisik}

Suhu rata-rata tahunan di Kota Denpasar berfluktuasi, suhu udara minimum adalah $23,7^{\circ} \mathrm{C}$ terjadi pada bulan September dan suhu udara maksinumnya adalah $31,1^{\circ} \mathrm{C}$ pada bulan Oktober (Denpasar dalam Angka, 2009). Kondisi tanah Kecamatan Denpasar Selatan dicirikan oleh relief datar dan dataran fluvial, sehingga beberapa kawasan terpengaruh oleh intrusi air laut. Tanah pada kawasan dekat dengan hutan mangrove 
merupakan tanah berlumpur yang berasal dari pantai dan endapan yang dibawa oleh aliran sungai.

Topografi di Restoran akame datar dan sebagian dekat dengan pantai sehingga dipengaruhi oleh pasang surut air laut. Topografi pantai merupakan faktor penting yang mempengaruhi karakteristik struktur mangrove, khususnya komposisi spesies dan ukuran serta luas hutan mangrove. Semakin datar pantai dan semakin besar pasang surut, maka semakin lebar hutan mangrove dapat tumbuh (Mangrove Information Center, 2004). Jenis vegetasi didominasi oleh tanaman mangrove antara lain: Bakau (Rhizophora mucronata), Mentigi (Ceriops tagal), Lindur (Bruguiera gymnorrhiza), Prapat (Sonneratia alba). Pada tapak juga ditemukan tanaman selain jenis mangrove antara lain Palem Putri, Cemara laut dan Lamtoro.

Beberapa jenis kepiting yang terdapat di area ini antara lain kepiting mangrove (Uca triangularis). Pada Restoran Akame juga dapat ditemukan beberapa jenis burung antara lain: Burung Udang Biru (Alcedo caerulescens), Crucuk (Pycnonotus aurigaster), Kokokan Laut (Butorides striatus), Burung Gereja (Passer montanus). Gambaran vegetasi jenis mangrove yang terdapat di Restoran Akame dapat dilihat pada Gambar 2.

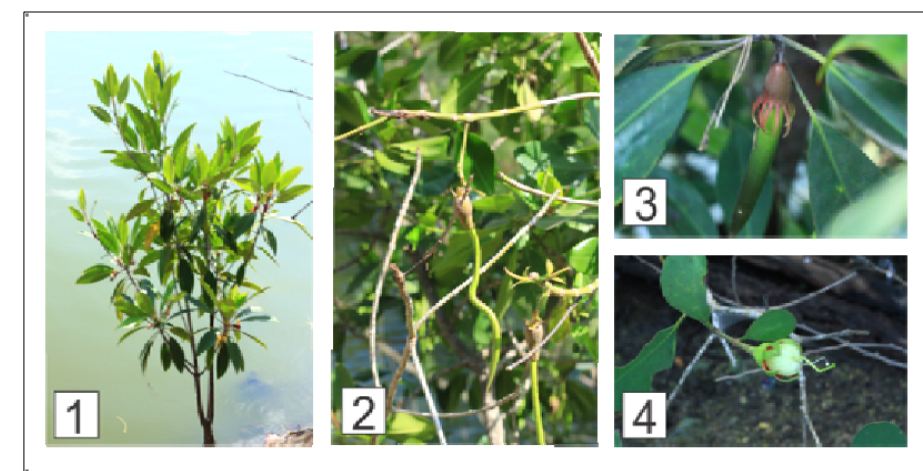

Keterangan: 1) Bakau (Rhizophora mucronata), 2) Mentigi (Ceriops tagal)

3) Lindur (Bruguiera gymnorrhiza), 4) Prapat (Sonneratia alba)

Gambar 2. Vegetasi Pada Lokasi Tapak

\subsubsection{Aspek Ekonomi}

Beberapa kegiatan kepariwisataan di daerah Denpasar Selatan banyak terpusat di Sanur, selain hotel dan penginapan di sekitar kawasan juga terdapat beberapa restoran dan pusat perdagangan. Terdapat pula beberapa sarana wisata lainnya seperti kolam pemancingan dan tambak udang disekitar kawasan Sanur. Pada Restoran Akame keberadaan mangrove sangat mendukung daya tarik wisata pada kawasan tersebut. Selain sebagai barrier, keberadaan mangrove juga sebagai daya dukung visual untuk menarik pengunjung untuk datang berkunjung.

\subsubsection{Aspek Sosial dan Budaya}

Aktivitas di dalam kawasan restoran sangat beragam, pengunjung biasanya menikmati makanan yang tersedia sambil duduk-duduk di gazebo dan ada pula yang sambil memancing. Wisatawan yang berkunjungan didominasi oleh wisatawan dari Cina, 
Taiwan, Korea. Pada aspek budaya di Retoran Akame terdapat beberapa tempat beribadah (pelinggih). Aktivitas religi yang rutin dilaksanakan setiap hari yaitu melakukan kegiatan yadnya (mebanten) oleh pegawai Restoran Akame. Aktivitas nelayan disekitar kawasan yaitu menangkap ikan dengan perahu yang bersayap dua agar seimbang, tetapi tidak sedikit yang menggunakan sayap penyeimbang yang hanya satu. Selain dengan memancing, nelayan juga menangkap ikan dengan menggunakan rumpon dari kayu.

\subsection{Pembahasan}

Restoran Akame sangat mudah dijangkau oleh masyarakat sebagai tujuan wisata karena berada disebelah kiri jalur menuju Tol Bali Mandara. Keberadaan kawasan Restoran Akame menjadi satu tambahan objek wisata di Denpasar khususnya di Denpasar Selatan. Pembentukan akses sirkulasi kendaraan pada tapak perencanaan diperlukan untuk menampung jumlah kendaraan di dalam kawasan wisata.

Suhu dan kelembaban merupakan faktor utama penentu kenyamanan dan aktivitas manusia (Nurisjah dan Pramukanto, 2007). Menurut Laurie (1986) dalam Nurfaida (1997), iklim yang ideal bagi kenyamanan manusia adalah udara yang bersih, suhu antara 50-80 $\mathrm{F}$ $\left(10-26^{\circ} \mathrm{C}\right)$, kelembaban antara $40-75 \%$, udara yang tidak terperangkap dan tidak berupa angin kencang. Suhu yang dimiliki kawasan Restoran Akame yaitu $25.4^{\circ} \mathrm{C}-28.7^{\circ} \mathrm{C}$, yang masih berada dalam standar kenyamanan manusia. Kelembaban yang cukup tinggi yaitu 74-83\% relatif nyaman untuk melakukan suatu kegiatan dan aktivitas wisata.

Keberadaan hutan mangrove yang masih alami pada kawasan memberikan kesan visual yang sangat baik (good view) bagi pengunjung kawasan. Memanfaatkan visual mangrove juga dapat menjadikan daya tarik pada suatu kawasan wisata. Dengan meminimalisir visual yang buruk kawasan serta penataan visual yang mendukung didalam tapak maka membuat kawasan wisata semakin diminati. Variasi vegetasi dalam kawasan relatif sedikit dan jenis tanaman yang paling mendominasi merupakan jenis tanaman mangrove. Penambahan vegetasi juga diperlukan sebagai tanaman peneduh dan penambah estetika dalam kawasan.

\subsubsection{Konsep Tata Ruang}

Di Restoran Akame terdapat tiga ruang yang dibentuk yaitu area untuk penerimaan, area aktivitas dan juga area penyangga tapak. Pada area penerimaan berfungsi sebagai pintu masuk utama untuk memasuki kawasan wisata mangrove. Area penerimaan juga dapat berfungsi menarik pengunjung agar tertarik mengunjungi kawasan wisata mangrove di kawasan Restoran Akame. Pada area penerimaan dibuat karakter ruang yang bersifat estetik dan informatif mengenai kegiatan wisata di dalam kawasan tapak.

Area aktivitas berfungsi sebagai pusat kegiatan wisata. Dalam area ini terdapat berbagai kegiatan wisata yang berhubungan dengan lingkungan tapak. Area aktifitas ini terdiri dari area budidaya kepiting, area pengamatan burung, area penanaman mangrove, area outbond dan perahu sampan. Area penyangga merupakan areal yang mengelilingi kawasan wisata. Area penyangga berfungsi sebagai areal pendukung kawasan wisata mangrove di Restoran Akame (Gambar 3). 


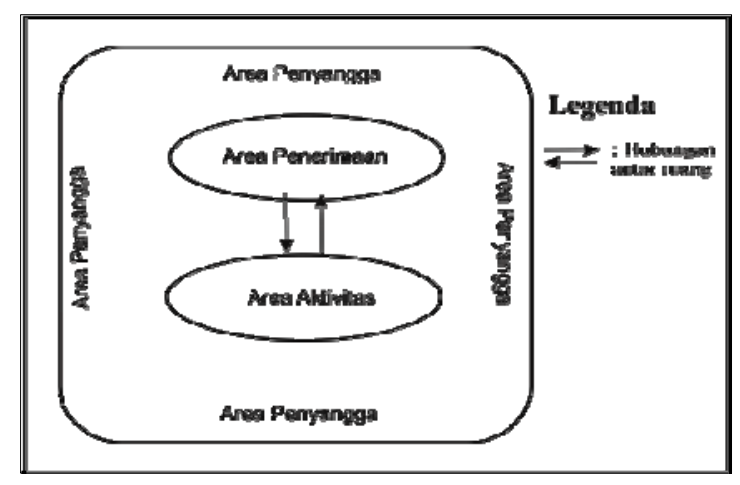

Gambar 3. Konsep Ruang

\subsubsection{Tata Sirkulasi}

Konsep sirkulasi yang direncanakan merupakan jalur-jalur yang menghubungkan antar satu ruang ke ruang lainnya serta menghubungkan antara satu objek ke objek lainnya yang terdapat pada tapak. Pengembangan sirkulasi ini dilakukan berdasarkan kondisi kebutuhan tapak dan ruang-ruang yang ada, sehingga konsep sirkulasi adalah membagi jalur sirkulasi berdasarkan kegunaanya (Simond, 2006). Konsep sirkulasi dibuat rotasi, sehingga semua objek pada tapak dapat dilalui. Sirkulasi yang direncanakan berupa sirkulasi primer dan sirkulasi sekunder. Sirkulasi primer yang dimaksud yaitu sirkulasi utama yang menghubungkan area penerimaan dengan area aktivitas wisata. Sirkulasi sekunder merupakan sirkulasi yang menghubungkan satu objek ke objek lainnya dalam area aktivitas wisata. Konsep sirkulasi ditampilkan pada Gambar 4.

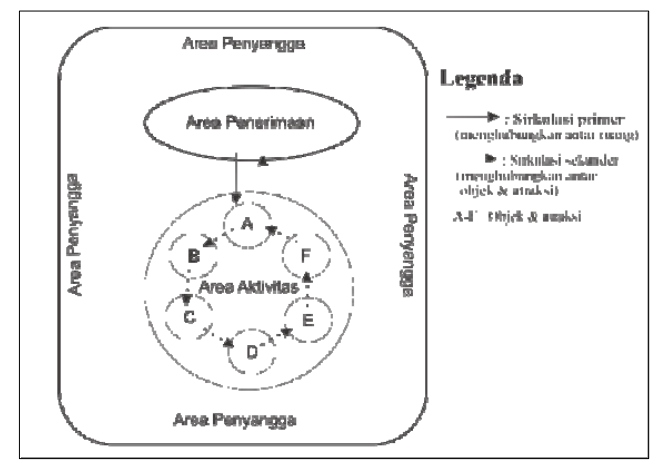

Gambar 4. Konsep Sirkulasi

\subsection{Tata Sarana dan Prasarana}

Konsep tata sarana dan prasarana yang dikembangkan bertujuan untuk mendukung kegiatan wisata yang direncanakan pada tapak. Fasilitas yang direncanakan disesuaikan dengan ruang dan aktivitas pengunjung tapak. Fasilitas wisata merupakan segala sesuatu yang berkaitan dengan penyediaan barang dan jasa ketika seseorang berada disuatu daerah tujuan wisata. Menurut Marpaung (2002), fasilitas wisata adalah segala sesuatu yang bersifat melayani dan mempermudah kegiatan atau aktivitas pengunjung yang 
dilakukan dalam rangka mendapatkan pengalaman rekreasi. Konsep tata sarana dan prasarana pada dasarnya terdiri dari tiga bagian yaitu area penyangga, area penerimaan dan area aktivitas (Tabel 1 ).

Tabel 1. Konsep Tata Sarana dan Prasarana

\begin{tabular}{|c|c|c|c|}
\hline \multirow{2}{*}{ Ruang } & \multirow{2}{*}{ Aktivitas } & \multicolumn{2}{|c|}{ Fasilitas } \\
\hline & & Sarana & Prasarana \\
\hline$(1)$ & (2) & (3) & (4) \\
\hline Area Penyangga & Memarkir Kendaraan & Areal Parkir & $\begin{array}{l}\text { Papan Informasi } \\
\text { Rambu-rambu }\end{array}$ \\
\hline Area Penerimaan & Penerimaan Pengunjung & Ruang Penerimaan & $\begin{array}{l}\text { Papan informasi } \\
\text { Ruang Souvenir } \\
\text { Loket karcis } \\
\text { Toilet }\end{array}$ \\
\hline \multirow{6}{*}{ Area Aktivitas } & $\begin{array}{l}\text { a. Pembudidayaan } \\
\text { Kepiting Mangrove }\end{array}$ & Kolam kepiting & $\begin{array}{l}\text { Papan Informasi } \\
\text { Sepatu boat }\end{array}$ \\
\hline & $\begin{array}{l}\text { b. Mengamati } \\
\text { Burung/Bird Watching }\end{array}$ & Menara Pengamatan & $\begin{array}{l}\text { Papan Informasi } \\
\text { Teropong }\end{array}$ \\
\hline & $\begin{array}{l}\text { c. Menaman Bibit } \\
\text { Mangrove }\end{array}$ & $\begin{array}{l}\text { Deck } \\
\text { Areal Penanaman }\end{array}$ & $\begin{array}{l}\text { Papan Informasi } \\
\text { Bibit Mangrove } \\
\text { Sepatu Boat }\end{array}$ \\
\hline & $\begin{array}{l}\text { d. Melakukan } \\
\text { Permainan Outbond }\end{array}$ & Area Outbond & $\begin{array}{l}\text { Papan Informasi } \\
\text { Peralatan Keamanan }\end{array}$ \\
\hline & e. Bersampan & Geladak terapung & $\begin{array}{l}\text { Papan Informasi } \\
\text { Perahu Sampan } \\
\text { Pelampung }\end{array}$ \\
\hline & f. Restoran & Bangunan Restoran & $\begin{array}{l}\text { Ruang Makan } \\
\text { Toilet }\end{array}$ \\
\hline
\end{tabular}

\section{Perencanaan Lansekap dan Aktivitas Wisata Berbasis Edukasi Mangrove}

Tahap perencanaan merupakan suatu tahap pengembangan dari konsep-konsep yang menghasilkan suatu rencana tapak (site plan). Tahap perencanaan ini meliputi perencanaan ruang penerimaan, ruang aktivitas dan ruang penyangga. Luasan ruang berbeda pada setiap segmen yaitu mengikuti kondisi pada tapak. Gambar siteplan perencanaan lansekap wisata mangrove ditampilkan pada Gambar 5. 


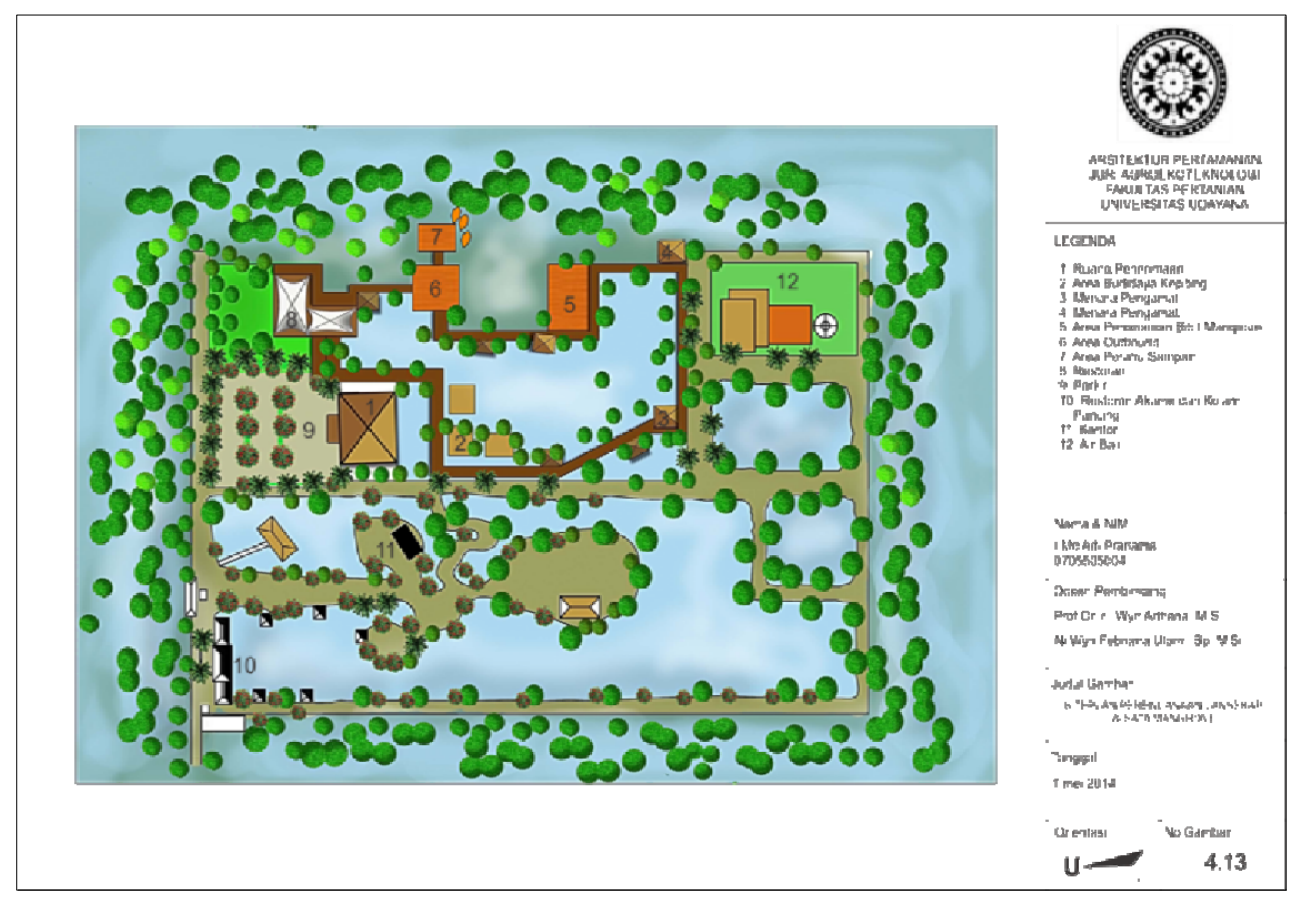

Gambar 5. Siteplan Perencanaan Lansekap Wisata Mangrove

Adapun perencanaan aktivitas wisata pada tapak berada di area aktivitas. Jenis aktivitas wisata yang direncanakan antara lain:

\subsubsection{Budidaya Kepiting Mangrove}

Aktivitas yang dilakukan oleh pengunjung di area ini yaitu memberi makan kepiting dan mencoba mengambil kepiting dari lubang dan sela-sela tanaman mangrove. Tujuan di adakannya kegiatan ini yaitu agar pengunjung kawasan wisata ini dapat mengetahui beberapa jenis kepiting yang hidup di area mangrove dan juga dapat berinteraksi langsung dengan kepiting mangrove. Area budidaya kepiting mangrove dibuat dengan sistem keramba tancap. Bahan pembuatan keramba tancap berupa potongan bambu dan jaring sebagai pembatas.

\subsubsection{Mengamati Burung}

Tujuan kegiatan pengamatan burung yaitu memberi pengetahuan kepada pengunjung tentang beberapa jenis burung dan bertujuan agar para pengunjung dapat melestarikan kawasan hutan mangrove sebagai habitat alami dari berbagai fauna termasuk burung-burung seperti Burung Kokokan Laut (Butorides striatus), Burung Udang Biru (Alcedo caerulescens), Crucuk (Pycnonotus aurigaster), dan Burung Gereja (Passer montanus).

\subsubsection{Menanam Bibit Mangrove}

Aktivitas yang dapat dilakukan di areal penanaman antara lain living class mangrove dan penanaman bibit mangrove. Lokasi penanaman bibit mangrove berada di tengah dari areal tapak dekat dengan kawasan hutan disebelah utara lokasi tapak. Bibit mangrove yang dipilih jenis bakau (R. mucronata) karena sangat cocok dengan penanaman langsung di daerah pasang surut dan tahan terhadap genangan air laut. 


\subsubsection{Outbound}

Pada permainan outbound pengunjung diharapkan dapat berinteraksi langsung dengan lingkungan mangrove. Selama permainan berlangsung dapat dimasukkan unsur kegiatan edukasi seperti melakukan permainan flyingfox sambil melihat mangrove yang ada di bawahnya dan nantinya menyebutkan mangrove yang dilihat, sedangkan dalam permainan jembatan tali pengunjung diajak untuk melewati jembatan sambil mengambil kertas yang berisi nama tanaman mangrove. Menurut Nurisyah (2006), melibatkan kelima panca indera anak-anak serta merangsang pemikiran edukatif mereka merupakan pendekatan yang dianjurkan bagi pengelola untuk menumbuhkembangkan keingintahuan anak-anak tentang kekayaan kawasan pesisir.

\subsubsection{Bersampan}

Pada saat berada di Restoran Akame, pengunjung juga berkesempatan mengelilingi kawasan mangrove menggunakan perahu sampan. Kegiatan ini juga berfungsi memberikan pemahaman tentang pentingnya tanaman mangrove dalam melindungi dan mengendalikan kualitas pesisir secara fisik dan bermanfaat bagi kehidupan nelayan. Area perahu sampan terletak disebelah utara dari area outbound.

\subsubsection{Wisata Kuliner}

Pengunjung dapat berwisata kuliner sambil beristirahat setelah lelah berkeliling di sekitar restoran merupakan aktivitas terakhir yang bisa dilakukan. Bertempat di Restoran Akame yang terletak di ujung sebelah barat kawasan wisata. Bangunan restoran dibuat terapung untuk menambah kesan alami dan kesan menyatu dengan areal sekitarnya yang berupa perairan. Pada area ini pengunjung disuguhkan dengan menu-menu yang dominan merupakan masakan dari hasil laut. Menu utama di restoran ini berupa kepiting yang diambil dari area budidaya kepiting.

\section{Simpulan dan Saran}

\subsection{Simpulan}

1. Identifikasi dan analisis potensi dan kendala aspek biofisik, ekonomi, sosial dan budaya pada pengembangan lansekap wisata di Restoran Akame menghasilkan konsep tata ruang, konsep tata sirkulasi dan konsep tata sarana prasarana yang mendukung kegiatan dan aktivitas wisata edukasi mangrove.

2. Konsep perencanaan wisata edukasi mangrove yang sesuai dikembangkan di Restoran Akame yaitu pengembangan wisata yang mampu memberikan pembelajaran bagi pengunjung tentang mangrove dan berinteraksi langsung dengan lingkungan mangrove. Objek dan atraksi wisata yang direncanakan meliputi pembudidayaan kepiting mangrove, mengamati burung atau birdwatching, menanam bibit mangrove, outbound dan menaiki perahu sampan.

\subsection{Saran}

1. Hasil penelitian perencanaan wisata di Restoran Akame ini dapat dilanjutkan pada tahap perancangan yang lebih detail pada objek-objek wisata yang telah direncanakan. 
2. Tahap perancangan sebaiknya mempertimbangkan kealamian kawasan dan menciptakan ciri khas pada lansekap.

\section{Daftar Pustaka}

Ambara, I G.A.G.2009. Wisata Hutan Bakau di Denpasar Selatan. Skripsi (tidak dipublikasi). Fakultas Teknik Universitas Udayana.

BPS. 2009. Denpasar Dalam Angka Tahun 2009. Badan Pusat Statistik.

Dinas Kehutanan. 2008. Hutan dan Kehutanan Provinsi Bali. Denpasar .

Firmansyah. 2006. Pengembangan Metode Assessment Kualitas Lansekap Kampus di Indonesia: Metode Assessment Deskriptif. Prosiding Simposium IImiah Nasional. Ikatan Arsitek Lanskap Indonesia. Bogor.

Inskeep, E. 1991. Tourism Planning.An Integrated and Suitainable Development Approach. New York.

Mangrove Information Center. 2004. Training Program for Suistainable mangrove Management in MIC. Bali.

Marpaung. 2002. Pengetahuan Kepariwisataan.Bandung: Alfabeta.

Nurfaida. 1997. Studi Rencana Pengelolaan Lansekap di Taman Wisata Alam Bantimurung Kabupaten Maros Sulawesi Selatan. Institut Pertanian Bogor.

Nurisjah, S dan Damayanti, V. D. 2006. Pengembangan Interprestasi Wisata Pesisir Guna Mendukung Program Pendidikan Sumber Daya Pesisir dan Kelautan: Kumpulan Riset Kelautan. Bogor.Nurisjah, S dan Q.

Pramukanto.2001. Perencanaan Kawasan untuk Pelestarian Lanskap dan Taman Sejarah. Bogor. Institut Pertanian Bogor.

Simond, J.O. 1983. Landscape Architecture. McGraw-Hill Book Co, NewYork. 